\title{
Collective Occupation in Public Spaces and the Construction of the Social Fabric.
}

\author{
Abstract \\ Background. Contemporary research is expanding understandings occupation beyond that \\ of the individual's doing, including the shared and social nature of occupation and the \\ concept of collective occupation has been introduced. Purpose. A study aimed to explicate \\ the concept of occupation in a Greek town Method. Ethnographic methodology was used and \\ primary data included observation, participation and informal interviews. Analysis involved a \\ hermeneutic process to develop a narrative of occupation in the town, including action, \\ setting and plots. Findings. Occupation, a dynamic and multidimensional process, served to \\ maintain the self, family and social fabric, and balance between and within them. Collective \\ occupation maintained the social fabric through three forms: informal daily encounters in \\ public spaces; organisation and associations; celebration and commemoration. Implications. \\ Occupational therapists may consider engaging with the potential power of such collective \\ occupation when working towards social change to enable just and inclusive societies.
}


From many parts of the world there are calls in the literature for occupational therapists to expand their practice to focus not only on change for the individual but also to work towards social change to enable, as Townsend, Cockburn, Letts, Thibeault \& Trentham describe (2013, p.154) "just and inclusive" societies. However, it has been argued that existing understandings of occupation relate primarily to the individual and are not easily applied when working with communities (Leclair, 2010). Research exploring the concept of occupation itself may reveal alternative understandings (Dickie, 2003), and challenge traditional positions within the dominant professional discourse (Hammell, 2014). One area of such research is moving away from a focus on the agentic individual towards exploring the shared and social nature of occupation, including forms of occupation beyond that of the individual doing alone (Fogelberg \& Frauworth, 2010), and collective occupation (Ramugondo \& Kronenberg, 2015). This paper contributes to this discussion by presenting part of the findings of an ethnographic study that aimed to conceptualise occupation in a Greek town, and particularly the findings regarding occupation in public spaces, the various forms of such collective occupation that were identified, and their relationship with the construction and maintenance of the social fabric. Occupational therapists working with communities may wish to consider these forms of occupation as more relevant to these settings and as important in processes of change and the construction of the local social world.

\section{Background}

The past 25 years has seen developments in the understanding of the social nature of occupation. In the early 1990's Pierce (2009) introduced the concept of co-occupation to describe the interactive shaping of two person's occupation. Although Pierce maintained that occupation as a concept should refer only to the individual's experience, later studies 
suggested co-occupation to be a transformation of occupation beyond that of the individual, incorporating "shared physicality, shared emotionality, and shared intentionality" (Pickens \& Pzur-Barenkow, 2009, p. 155).

This notion that some occupation is of many people rather than individual, with a shared form and experience, was developed by Fogelberg and Frauworth (2010), who suggested that national holidays, sporting events and national elections (for example), should be considered distributed occupations. They used systems theory to understand the collective production of such occupations across four nested levels: population, community, group and individual, where each level is a complex system which produces and self-organises around occupation. At population, community and group level no one individual can account for the occupation that takes place as a whole. The occupation is distributed across the people taking part in a multitude of ways, and the occupation produced has a synergistic, gestalt quality. Their work provides a framework through which to describe forms of naturally occurring occupation produced by larger social groups. It also supports a more complex and multidimensional view of agency, underpinned in their work by dynamic systems theory, but also evident in a transactional perspective of occupation (Cutchin \& Dickie, 2013).

That individualistic views of occupation are embedded in Western cultural positions has been discussed in relation to more collectivistic Eastern world views (Iwama, 2006). Ethnographic research in Honduras, Morocco, Burkina Faso, Tanzania and Ecuador described occupation as social practices inextricably linked to context (Zango Martin, Flores Martos, Moruno Millares, \& Björklund, 2015), with such occupation categorized as co-occupations, collective occupations and collaborative occupations.

However, the dichotomy of individualism and collectivism was challenged by Ramagundo and Kronenberg's (2015) theoretical discussion of the concept of collective 
occupation. They emphasised the interconnectedness between the person and the social underpinned by the African value of Ubuntu. Rather than focusing on forms of collective occupation they focused on its intentionality, defining it as "occupations that are engaged in by individuals, groups, communities and/or societies in everyday contexts; these may reflect an intention towards social cohesion or dysfunction, and/or advancement of or aversion to a common good" (Ramagundo \& Kronenberg, 2015, p. 17). Evident in this definition is recognition of a relationship between the occupation of the collective and the construction of the social world. This was also discussed in Peralta-Catipon's (2012) ethnographic study of Filipino guest worker's collective occupation in Hong Kong that was identified as reconstructing a similar social structure to that of their home country. Adams and Casteleijn (2014), through a case-study design, identified collective participation, and the resulting gestalt, as enabling a collective vision and community development in South Africa.

However, a critical approach indicates the importance of recognizing the nature of the social world produced through collective occupation. Angell (2014) identified hegemonic practices related to gender, race, ability, and age in US schools, and a qualitative study in South Africa framed violence in this context as collective occupation incorporating the important notion of intent (Motimele \& Ramugondo, 2014).

While the literature is not extensive, it is nevertheless diverse in its representation of perspectives and in the terms adopted. It is both theory driven as well as research based, with qualitative studies including ethnography, providing depth and breadth to the discussion. Two key ideas have emerged through these studies: that much occupation is social and interrelated in form, and that this occupation is important in the construction of the social world.

This paper contributes to this discussion through the presentation of part of the findings of a study that aimed to explore occupation in a small Greek town (Kantartzis, 
2013). The study was developed in response to understanding of the cultural relativity of occupation and its conceptualizations (Kantartzis \& Molineux, 2011). This position was supported by the lived experience of the first author located on the borders between the English speaking academic/professional world (as a British born and educated occupational therapist) and the Greek world, lived professionally and personally for many years. In this paper findings related to collective occupation and the construction of the social world will be presented.

\begin{abstract}
Aim
The study aimed to explore the everyday activities of adults living in a small Greek town.

\section{Method}

The study employed an ethnographic methodology within an interpretivistconstructivist paradigm to explore the everyday occupation of people within the settings of their lives (O'Reilly, 2012). Ethnography enabled exploration of the tacit knowledge, including the shared meanings and understandings, of what is usual or ordinary everyday life (Bruner, 2008) and of the everyday occupation that is constructed from and re-constructs these meanings (Alsaker, Bongaardt, \& Josephsson, 2009). It was understood that there are multiple, equally valid, social realities, and that findings would be a co-construction between the researcher and the participants. Ideas from a critical theory perspective were incorporated, particularly regarding the reality of power and how social and ideological structures shape or influence action and the meaning of action (Denzin \& Lincoln, 2005).
\end{abstract}


Ethical approval for the study was obtained from the Faculty of Health Research Ethics Committee of Leeds Metropolitan University, UK. The town, all people and any identifying places were given pseudonyms.

\section{Setting and Data Collection}

The study was conducted in Melissa, a market town in central Greece with a population of about 3000 people. The town had been known to the first author (the researcher) for about 10 years and this existing relationship facilitated data collection through some awareness of the complex web of relationships inherent to any community.

Over a 30 month period between 2009 and 2011, 270 days were spent in the town. Primary data were observations, experiences of participation and conversations. The researcher, alongside the ongoing process of living daily life in the town, spent time with approximately 50 people. Formal interviews were conducted with some, for example, with the presidents of local associations; with others there were frequent, informal, encounters throughout the town; and with 10 people there was regular engagement in occupation. Local documents and websites provided additional information, while national and international events with potential impact were noted. Field notes were completed after each encounter or event. The researcher, always kséni (foreign) but at the same time "allá eínai dikí mas” (but she is ours), engaged in a process of being with the participants (Corbin-Dwyer \& Buckle, 2009) in multiple and varied ways as the research process developed. A diary, kept throughout, enabled an ongoing process of reflexivity.

\section{Data Analysis}

Initial data analysis developed categories and coded the large amount of field notes (Davies, 2008). In continuation, underpinned by Ricoeur's (1984) theory of mimesis by which daily activity was understood as the pre-verbalised stage of the shared stories of the 
town, analysis became a hermeneutic process of emplotment and to develop a narrative of everyday life in the town. The circular process of philosophical hermeneutics, as described by Gadamer (2004) and developed by Ricoeur (1991) was undertaken, involving an ongoing interpretive interplay between parts and whole (Alsakar \& Josephsson, 2011) together with a continual awareness of the position of the researcher. Gradually, a consistent interpretation was developed of occupation in the town. Three plots expressed the reasons "with which" (Ricoeur, 1991, p. 188) things were done: maintaining the self-in-the-world, maintaining the family, and maintaining the social fabric; three locations of needs and purpose of occupation. A transactional perspective (Cutchin \& Dickie, 2013) underpinned theoretically understandings of occupation as a dynamic and multidimensional process, maintaining balance between the multiple and changing elements of the total situation, conflicting needs and purposes (Kantartzis, 2013).

The discussion here will focus on the third plot, maintaining the social fabric, and particularly on collective occupation which primarily (re)constructed its particular nature. Data in the form of extracts from the field notes together with discussion and interpretation are intertwined within the narrative that is presented.

\section{Evaluating Quality}

Rigour of method (Guba \& Lincoln, 2005) was ensured through the use of the wellestablished methods of ethnography enabling the exploration of daily life at multiple levels, the extended period of time spent in the town with detailed fieldnotes, and the ongoing reflexivity of the researcher captured in the reflexive diary and supervision. Rigour of interpretation (Guba \& Lincoln, 2005) in a hermeneutic approach involves endeavouring to develop the best possible interpretation. Multiple data sources, including numerical data and 
emic categories, ongoing discussions with townspeople and observations, strengthened the development of the interpretation.

\section{Findings}

\section{Maintaining the Social Fabric}

The phrase social fabric was used to describe a location of purpose of occupation beyond that of the self and family. It implies not only the importance of the social world, but also a structure that is complex, irregular and dynamic, with potential to be tight knit or fragile. The phrase is also a powerful metaphor, and as the economic crisis of 2008 emerged in Greece during the time of the study, it was frequently used in national and international newspaper reports to demonstrate the perceived threat by the crisis to the cohesion of society. The phrase was therefore not only relevant to the findings of this study, but also to the broader context of the times.

The social fabric refers to the interpersonal relationships between the various people of the town, and the nature and strength of those (Ahlbrant \& Cunningham, 1979). It implies a public world (Arendt, 1958), taking place beyond the home or work place, created and recreated by people coming together in collective occupation. Three forms of such occupation were identified - informal daily encounters in public spaces, local organisation and associations, and celebrations and commemorations - three distinct forms of occupation that offered particular possibilities for action, social interaction, and experience, and were thereby reconstructed. Although they will be discussed here as three distinct forms, in practice these were more fluid and overlapping than such naming implies.

In the study the word maintaining (the social fabric) was used to emphasis the dominance of conservative beliefs within the town, of traditional practices and particular groups, the exclusion or marginalisation of other groups, and a resistance to change. 
Alternative, conflicting narratives were also evident, for example, towards development and change, highlighting the discrepancy and unique aspect of the social fabric that emerges from each social group and context.

\section{Informal Daily Encounters in Public Spaces}

The collective occupation of informal daily encounters in public space did not always include a large number of people doing occupation together but rather was interlinking networks of occupation. An intricate interweaving of individuals' routines through the familiar public spaces of the immediate neighbourhood around the home, the public squares and the surrounding shops, coffee-shops and tavernas, aptly described by Seamon (2013) as a place ballet, facilitated the daily (re)construction of the ongoing flow of interrelated occupation.

Informal daily encounters took a variety of forms. For many men, their local steki (haunt), one of the coffee shops in the town, was as familiar as their own home, and a place of daily encounters with their parea (companions), as Stathis, a farmer in his mid 80's described:

He had been to Anna's kafeneío for a coffee at seven o'clock in the morning. He told me that actually, he doesn't like coffee. "But", as he said, "if you go to the kafeneío at seven in the morning what can you drink - ouzo, beer? No, I go to see what's happening, what news there is, what everyone is going to be doing, and at my age, to see who's died". Another morning when I bumped into him, he told me he had finished his jobs by eleven and was going for an ouzo with his paréa (companions) at Anna's again. In the early morning his paréa may not be there, "it is not compulsory attendance" he jokes, but at eleven they all meet. He went again at six in the afternoon and usually two or three friends would pass by. He says he cannot let a day go by that 
he will not pass through the square. When I ask him why, he replies "if I don't go one day, and Christos doesn't the next and Petros the next..."

He left the sentence hanging, inviting reflection on the impact of such absences, the threat to the social fabric, to the ongoing network of occupation.

The occupations of going for a coffee, buying the daily bread, standing and chatting on the street corner or sitting with neighbours, offered the opportunity to enter the flow of the town's social life. By going out of their homes and into public space people learnt the news and formed an opinion about it, moved out of the intensity of family life within the home, shared practical advice and found help with a particular task, conducted a business deal, arranged social events, holidays and meetings etc. People frequently talked about this as a need they experienced; a need to go out, to be out, to join the social world.

Small acts of giving were an important aspect of these encounters, as a young woman, Maria, described:

If you cook something you take some to the neighbour, or to the old woman who lives downstairs. And if they cook something that they know is your favourite they will bring you some. And you never return a plate empty, you always put something on it, a couple of chocolates, some fruit, some pieces of pie...

Such exchange, as another woman, Martha, explained, "helps the trivi" (trivi, meaning to rub together), demonstrating her awareness of a social 'rubbing together' that preserves the social fabric. Food was shared by both men and women in a variety of forms, portions of prepared dishes, small handfuls or bags of seasonal fruit, nuts and vegetables, and small cakes on one's Saint's Day, shared during informal meetings in public places. In the 
coffee-shops men and women treated each other to their coffee on a daily basis, and treated visitors and business associates as well.

Exchange included the notion of obligations, arising within the network of relationships and occupation, and which people recognised and supported in varying ways and degrees. For example, Ketty went alternatively to three butchers; one was her cousin, one a school mate of her son and one a neighbour. "What can you do?" she asked me rhetorically "you do what you can"; in this way expressing how you do what you can to support the people you know, and to preserve connections. Maintaining the social fabric through the network of occupation was, for many, a conscious, deliberate process.

However, this network supported a hegemonic social order, primarily through the close-knit networks of the long established families. Newcomers to the town saw their attempts at touristic development resisted, because, as I was told "They [the locals] say they will not serve others". The ksenos (the stranger or foreigner) engaged in a slow process of becoming a gnostos (literally: known, and thereby trusted), and so increasingly bound within the network of occupation. Inclusion was neither a fixed state nor a linear process. Desired in different ways and to different degrees by each person and shaped by the existing network, it was fragile and dynamic, disrupted by events and changing circumstances, behaviour and conformity to social norms. Hard work, trustworthiness, gender appropriate behaviour and recognition of obligations, were observed, commented on, approved or not. One 'foreign' wife (from another country) was quickly approved of as, I was told, her actions showed her to be "a proper wife and mother". Another (recently moved from Athens) told me angrily that she would never fit in as "they don't let you". Businesses were made by the support of the network, but also damaged when support was withheld. A shop owner, Cathy, noted how when in financial need the townspeople had been active in their support for her business. 
However, once her children had been successful in gaining admission to prestigious universities, custom had dropped significantly.

Informal daily encounters may be considered as numerous threads that linked throughout peoples' daily lives, in an ongoing (re)construction of a network of occupation that was dynamic, continually readjusting to the changes in the multiple elements of the situation (Dewey \& Bentley, 1949). It not only shaped the form of individual's occupation but also incorporated trust, the sharing of skills and knowledge, promoted a sense of belonging, of being recognised by others, of being known, and of being part of a whole that was valued and significant. Conversely, as noted, it also worked to exclude and discriminate, marginalizing certain groups and individuals, and limiting creativity and innovation.

\section{Local Organization and Associations}

A second form of collective occupation organized the social fabric of the town, particularly in the form of local associations. Some of these represented and supported the rights of specific groups within the town, (e.g. the Young Peoples' Association), while others represented commercial interests (e.g. the Farmer's Cooperative). Other associations focused their activities on children's education and activities (e.g. the Scout Group), the local heritage and traditions (the Folk Lore Association), and specific recreational activities (e.g. the Athletics Association). These associations were founded locally following national legal requirements and provided the town as a whole with access to national bodies and funding opportunities, as well as opportunities to regulate local affairs in accordance with local issues and needs.

The importance of such collective occupation to respond to contemporary needs was evident in two developments that occurred during the course of the study. They demonstrate the dynamic nature of the social fabric and the contested nature of change. The first was the 
founding of two new associations. The Association for Touristic Development was established by a small number of hotel, restaurant and shop owners to promote the tourism they perceived to be essential for economic development in the town, and which was resisted by the dominant farming families supporting traditional ways of life. The second Association, the Citizens Initiative, was founded by a group of townspeople to actively promote quality of life in the town, largely in response to the reduced activities of the town council due to the ongoing, from 2008, economic crisis.

The second development illustrates how such collective occupation may not be organized through specific associations, but may emerge more informally to organize or shape occupation in public space. On news of the central government's decision to reformulate municipal boundaries to the perceived disadvantage of the town, a large number of townspeople spontaneously met outside the municipal buildings, demanding information and action. At an open meeting the large number of people present voted for specific action. Four coach-loads of townspeople travelled to Athens to take part in a demonstration outside the relevant ministry, while a few weeks later many participated in a blockade of the national train line.

The reasons that people participated in the associations, and in the informal action previously described, varied. A young farmer, Michaelis, had a vision of the town as a thriving community and a good place to bring up children, leading him to be a member of a number of associations and the town council. Others appeared to be interested in the recognition that accompanied participation, as Mr Sakkas, an active president of one association described: "they're all happy to sit in the square and proudly say they are on the board of this or that association..." Maria became president of one association "so they can see who I am". However, there was also a strongly perceived importance of participating in 
ta koina (the common), as Nikos, 78 years old, said: "I was involved in everything, everywhere, in associations here, for the children, at the school, with the sports, president, treasurer, I hadn't missed from anything..." Frances, a mother with two teenage children had participated "you know, to support the activities for the kids. And it gets you out of the house."

While people participated for various reasons, this collective occupation of the public world, offered a variety of opportunities other than those available at work or home. These included opportunities to use other skills (both practical and social), to have a voice in decisions and affairs that influenced the town, to be seen and recognized by others, and to do something different with others. While these opportunities were primarily part of the functioning of the associations, the mass support for the demonstrations against the new municipal boundaries demonstrated the possibility and importance of collective action beyond existing organized structures. Such action emerged spontaneously, but had its roots in the daily encounters that opened a public space for debate, and the perceived possibility and necessity of collective occupation to give voice and shape action around important issues when required.

\section{Celebratory and Commemorative Occupation}

The third form of collective occupation identified in the town was celebratory and commemorative. Some such occupation took place almost monthly throughout the year for the town as a whole. It included religious events, such as celebrations of Easter, blessings (of homes, schools and businesses), and church services marking life transitions, while others were secular, for example Carnival, the annual Bazaar and cultural events. Other events were commemorative, for example, Independence Day, and for those killed during the World Wars. On a weekly basis the local nightclub, tavernas and bars also offered places for 
celebration. Most events took place in public space, open to all inhabitants, while others took place at home or in the neighbourhood with more limited participants. These collective occupations can be seen as important social rituals incorporating people coming together, shared action and shared emotion producing a moment of shared reality, leading to the renewal of the group's solidarity, and individual emotional energy (Collins, 2004). The process of preparation for these, frequently involving symbolic objects and occupations, was also a key feature.

Celebratory events were anticipated and welcomed as a break from the routine and mundane, transforming the usual in multiple ways. For example, the choir's practicing of loud and bawdy carnival songs shocked Frances: "the old women belt out the words...You'd never hear them saying those words at other times.” These events required preparation: alternative clothes, food, hairstyles, cutting and storing wood for the Bonfire, constructing floats for the Carnival parade, and seasonal goods available in the shops. The physical space changed either because of the alternative use of public space, as when the week-long annual Bazaar took over the main road, or as the home was transformed with extra tables, chairs and settings for 20 or 30 people. Preparations were important in creating a sense of anticipation, of excitement. At the Day Centre Mr. Kosta hummed the tunes to himself and grinned wickedly when asked what he was singing, while other people agreed when he said: "it's good, you need a chance to ksespásei (break-out)."

This was a phrase frequently heard. It was important and necessary na ksespáseis (to break out), and na glentás (to revel), in order to regain balance of the self from the efforts of day to day living, whether during a Saturday night out or a special event. The experience of heightened emotion was anticipated as central to the actual duration of the event, and ideally for the experience of kéfi. Kéfi is usually translated as the spirit of joy, passion or high 
spirits. To come to kéfi was the optimum evening out, when one might "dance with your soul", forgetting everyday worries in the enjoyment of the moment. Going out in a large group of one's paréa (companions) was essential to having a good time, incorporating group jokes and banter, treating each other to drinks or food, ordering a favourite song for dancing. Kéfi was only possible within the collective occupation of going out with others.

Celebratory collective occupation usually incorporated traditional singing and dancing, many with lines of people holding each other's shoulders, a moment of shared action (Collins, 2004), through which one's place in the social fabric was embodied (Cowan, 1990). At the Bonfire:

The crowd around the fire was five people deep. The Mayor took the lead in the first dance around the whole fire. A long chain of 30 or 40 men, women and children aged 2 to at least 80 , holding each other's shoulders and facing the fire, danced an ongoing slow dance. When the Mayor dropped out the lead was taken up by someone else. The music did not stop for the next four or five hours, leading seamlessly from one dance to the next, and people dropped in and out of the dancing chain as they chose.

Celebratory and commemorative occupation also offered opportunities to experience being part of the whole, the opportunity to go out of the home and to meet up with one's paréa (companions), friends or family. Maria explained the large turnout at an Association's annual meeting: "it's an opportunity to get out of the house, and we'll go for a coffee with friends afterwards". These were opportunities to feel connected and engaged with not only the spiritual but also the social world. They created an ongoing sense of identity in relation to the town itself, a link to traditions and to the past. A number of commemorative events, for example, for townspeople who died in the Second World War, provided a space for collective mourning and remembrance as well as pride. Those closely related to the events were given 
the opportunity to have their story heard by their fellow citizens, to have their loved one publically recognized and reaffirmed as part of the history of the town.

Celebratory and commemorative occupation was an important part of the social fabric, transforming the everyday, while anticipation and preparation fueled the heightened emotion that would be experienced during the course of the event, and confirmed ones place in the whole.

\section{Discussion}

The findings of this study contribute to discussions extending understandings of occupations as they are traditionally considered from the individual's perspective and beyond the commonly stated purposes. For occupational therapists working with communities towards social change, these findings support the importance of recognizing: the various forms of collective occupation that are different from the occupation of the individual; public space as the space of collective occupation; and the significance of collective occupation in constructing the nature of the social fabric.

Given the range of terminology in use, it is proposed that collective occupation be used as an umbrella term that may incorporate various forms of occupation (for example, the three forms outlined in this study). It is proposed that collective occupation be defined by its unique construction through the numerous people engaged in it and the power that is thereby produced, as well as by its intention or purpose towards the social fabric.

\section{Forms of Collective Occupation}

This study supports that literature which has noted that there are forms of occupation which are essentially social, a gestalt different from the occupation of the individual (Fogelberg \& Frauworth, 2010). Arendt (1958) used the term Action, to describe the 
particular form of activity that is the coming together of people. She emphasized the importance of "sheer human togetherness" (Arendt, 1958, p.180) and the potential power when people come together, creating the common or public world where they have the opportunity to fulfill their identity and their potential.

It is proposed that the forms of collective occupation described here are uniquely constructed by "sheer human togetherness", are more than the sum of the individuals participating, and have a dynamic and a power unique to that togetherness. This supports discussions of the essential inter-relatedness of people (Ramagundo \& Kronenberg, 2015), linked to experiences of belonging and connectedness (Hammell, 2014). The traditional categorisations of occupation, such as productivity, leisure and self-care, have been critiqued as not fitting well with community development practice (Leclair, 2010). The three forms of collective occupation identified here may be seen as a tentative step in developing a typology that moves beyond a perspective that focuses primarily on the individual's occupation.

The first form, of daily encounters in public places, establishes and maintains informal networks of occupation and thereby the particular nature of the social fabric (also seen in Peralta-Catipon's (2014) discussion). Here, what one does, where, when and with whom is shaped by related occupation; knowledge, skills, products and support are exchanged, and one is recognized and given identity as an inextricable part of the social (Arendt, 1958; Hammell, 2014). The importance of these daily encounters is reflected in the discussions in the community development literature of locality development approaches, and of the importance of developing connections through nurturing local partnerships enabling shared planning and action (Laukner, 2010, Townsend et al., 2013). However, occupational therapists need to be aware of the particular power of such networks of occupation to shape everyday life, including to discriminate, isolate, stigmatize, approve social behaviour (or not), 
controlling what individuals or groups can or cannot do, the recognition and the place they are awarded, and their sense of belonging.

Secondly, the collective occupation of organization and associations is the joining together of people to debate, protest and support, to shape common actions and to organize the public world. In Melissa it has been seen how this collective occupation emerged spontaneously to address local needs, and in this emergent process daily encounters were particularly important. This is the form of collective action most frequently discussed as participation in civic society and a key component of citizenship. Laukner (2010) demonstrates how occupational therapists facilitate such collective occupation when enabling programmes and projects in the community that build consumer and community capacity. As demonstrated in Melissa the importance of such occupation is not only in the cooperation, reciprocity and solidarity demonstrated, and in the positions of power and responsibility offered individuals, but also how through this process occupations are named and given particular forms (e.g. associations), including and excluding in their structuring, and creating social patterns (for example, grouping women, parents and young people in different associations). Importantly such collective occupation may also be a vehicle of social change, as in the demonstrations against the new administrative boundaries in Melissa, and in Frank and Muriithi's (2015) discussion of the American civil rights movement. Developing the theory of occupational reconstructions they discuss social movements arising from an awareness of deficit or injustice and a collective desire for social transformation. Such theoretical developments, recognising not only the power of the collective to structure the social world, but harnessing that power to enable change in problematic situations, is important in supporting occupational therapists who wish to work with complex collective issues of injustice and exclusion. 
The third form of collective occupation of celebration and commemoration recognizes the opportunities for heightened emotional experiences that the coming together of people can bring. Rituals and traditional community events take many different forms throughout the world, but the experience of heightened, intense emotion is common (Von Scheve \& Ismer, 2013), whether that is related to the joy of kefi, or shared empathy and grieving. Where traditional rituals are less common, other forms of heightened collective emotion may be enabled, for example, in sports-crowd's chanting and Mexican waves, flash mobs and pop concerts (Getz, 2007). Such occupation is important for generating solidarity and common symbols (Collins, 2004), and therefore may be particularly important for occupational therapists working with increasingly diverse and mobile populations.

Further study is required to explore how these three forms of collective occupation are constructed, their inter-relationships and their potential for social change. Such collective occupations are not social institutions shaping the activity of the passive individual, but rather only exist in the coming together of people. The power created by that coming together creates and maintains the public world.

\section{Public Space}

The public world is both physical and social space; locations where people can come together as well as places of appearance and recognition (Arendt, 1958). This is a space beyond the home and the work place. Traditionally the well, market place, as well as the pub and the coffee shop were such locations (Oldenberg, 1997). The importance of local spaces and how people may move through those creating opportunities for interaction and the development of networks is vital here (Seamon, 2013). Occupational therapists working with community development should consider how such spaces may be supported or developed, as well as the possible loss or diminishing of such public spaces for collective expression and 
action. For example, the increasingly urbanized, privatized and Neo Liberal world may marginalize through membership processes, admission charges and costs, move on those considered undesirable, or exclude through language or culture. Collective action, the action of the crowd, often accompanied by enhanced emotions, may be perceived as a threat to macro institutional structures, with enforced control on public debate and gatherings.

This study supports the importance of occupational therapists to work within this meso level of the public world. Brazilian occupational therapists talk of working with 'a territory', a physical location, in their social practice (Serrata Malfitano, Esquerdo Lopes, Magalhaes \& Townsend, 2014). In Canada the term community may refer less to a geographical location and more to people sharing common experiences (Townsend et al. 2013). However, this requires consideration of who is included and excluded in the 'community', what norms and values are supported, and what occupation is prioritized. Angell's (2014) analysis identified the classroom and the playground as sites of both resistance and reproduction of the social order, while Ramugondo and Kronenberg (2015) noted how collectives must recognize their "intentional stance" (p.10) that results in the exclusion and inclusion of particular individuals or populations, rather than blaming societal organisation. The importance can be seen of recognizing how people are and what they do together in our shared public world, as fellow citizens (Fransen, Pollard, Kantartzis, \& VianaMoldes, 2015), and the spaces available for such engagement.

\section{Collective Occupation and the Construction of the Social Fabric}

'Maintaining the social fabric' was one of the three plots developed in the narrative of daily life in Melissa. The social fabric, understood as threads of connection and interrelationships, a social world, was constructed and reconstructed through the particular forms of collective occupation. Its nature, its strengths and weaknesses, was constructed by 
the people of Melissa coming together in public space, through the power of their togetherness. The existence and importance of this social, public world, was recognized by many people in Melissa and expressed as a need to go out, to be out and to be part of the social flow. This was something other than, and further than, a need to be with others, potentially satisfied by family and friend relationships. The public world, and being part of that world through collective occupation, was a unique source of opportunities and experiences.

While it is proposed that it is useful for practice to focus on this meso, collective level, inevitably the individual and the structural are inter-dependent and interlinking domains. In Melissa a pleurality of action, voices and entities was seen, across self, family and social within the context as a whole (Cutchin \& Dickie, 2013).

\section{Limitations}

A number of limitations of this study are acknowledged, including its specific geographical location in Southern Europe. While the first author's position allowed a slightly widened horizon (Gadamer, 2004) from which to develop understanding of occupation, this was also limited by the depth of her knowledge of local language and culture. The construction of the narrative involved the active interaction of the researcher with a particular group of people over a limited period of time (Lawlor \& Mattingly, 2001) and the perspective on the world of the town presented is potentially one of many, and is also provisional as events are in constant flux. Readers should engage with this reflection within their own world (Ricoeur, 1991).

\section{Implications for Occupational Therapy Practice}

Recognising that there are various forms of collective occupation, enables occupational therapists to consider the nature of each form within the locality or community 
with which they are working, as well as the potential for developing, strengthening or expanding these. Further research will further identify the processes and outcomes of such approaches.

This study also suggests the importance of a common public world, which optimally provides a place for action and of recognition for all. While occupational therapists may be familiar with the notion of developing "safe havens" (Pinfold, 2000, p. 208) in the community for particular client groups, the notion of developing public places inclusive for all citizens needs further development. How this may be achieved in large urban areas with little or no common or safe public spaces requires consideration.

Working towards social change is not unique to occupational therapy, and collective occupation may be seen to be related to a number of concepts from other disciplines and these relationships require further exploration. For example, strong links can be seen between networks of occupation constructed through daily encounters and social capital, when understood to be accessed through social relations (Coleman, 1988). Further study may also explore the importance of collective occupation to the emergence of collective emotion and emotional energy (Collins, 2004), and the role of such experiences not only in relation to solidarity but also to balance hard work and refresh the soul, as experienced in Melissa.

\section{Conclusion}

This study contributes to discussions in the literature of collective occupation and the relationship between such occupation and the social world. It is proposed that collective occupation is a useful umbrella term for a variety of forms of occupation, which share certain distinctive features: they are constructed through the complex and multiple interactions of numerous people in public space, and through the power so created construct and maintain 
the social fabric. The nature of that fabric, its strengths and its weaknesses, is determined by the nature of the collective processes occurring.

Collective occupation has been suggested as important for opening up new perspectives for practice whether working primarily with individuals or communities (Kronenberg, Pollard, \& Ramugundo, 2011), and this study has supported the centrality of collective occupation to everyday life and therefore its importance in occupational therapy practice. It is proposed that occupational therapists working towards social change, for example through community development, consider collective occupation as central to these processes of change.

\section{Key Messages}

- Collective occupation is occupation unique to the coming together of numerous people and enables experiences different to that of the individual doing alone.

- Public spaces, both physical and social, are important for collective occupation.

- The meso level of the social world, described as the social fabric, is constructed through collective occupation and is important in enabling or not inclusion.

\section{Acknowledgements}

The authors gratefully acknowledge the comments and suggestions of Gelya Frank, $\mathrm{PhD}$, Professor, Mrs. T. H. Chan Division of Occupational Science and Occupational Therapy, University of Southern California, in the development of this paper. Also, Sally Foster, of Leeds Beckett University, UK, who was director of the first author's doctoral studies, upon which this paper is based. 


\section{References}

Adams, F., \& Casteleijn, D. (2014). New insights in collective participation: A South African perspective. South African Journal of Occupational Therapy, 44(1), 81-87.

Ahlbrant, R. S., \& Cunningham, J. V. (1979). A new public policy for neighbourhood preservation. New York: Praeger.

Alsaker, S., Bongaardt, R., \& Josephsson, S. (2009). Studying narrative-in-action in women with chronic rheumatic conditions. Qualitative Health Research, 19, 1154-1161. doi: $10.1177 / 1049732309341478$

Angell, A. M. (2014). Occupation-centered analysis of social difference: Contributions to a socially responsive occupational science. Journal of Occupational Science, 21, 104116. doi:10.1080/14427591.2012.711230

Arendt, H. (1958). The human condition (2nd ed.). Chicago: The University of Chicago Press.

Bourdieu, P. (1977). Outline of a theory of practice (R. Nice, Trans.). Cambridge: Cambridge University Press.

Bruner, J. (2008). Culture and minds: Their fruitful incommensurability. ETHOS, 36, 29-45. doi: 10.1111/j.1548-1352.2008.00002.x

Coleman, J. S. (1988). Social capital in the creation of human capital. The American Journal of Sociology, 94, Supplement, S95-S120.

Collins, R. (2004). Interaction ritual chains. Princeton: Princeton University Press.

Corbin-Dwyer, S. \& Buckle, J. (2009). The space between: On being an insider-outsider in qualitative research. International Journal of Qualitative Methods, 8, 54-63

Cowan, J. (1990). Dance and the body politic in Northern Greece. Princeton, NJ: Princeton University Press. 
Cutchin, M. P., \& Dickie, V. (2013). Transactional perspectives on occupation. New York, NY: Springer.

Davies, C. A. (2008). Reflexive ethnography (2nd ed.). London: Routledge.

Denzin, N. \& Lincoln, Y. (Eds) (2005). The Sage Handbook of Qualitative Research $3^{\text {rd }}$ Ed. Thousand Oaks: Sage Publications.

Dewey, J., \& Bentley, A. (1949). Knowing and the known. Boston: Beacon Press.

Dickie, V. (2003). The role of learning in quilt making. Journal of Occupational Science, 10, 120-129. doi:10.1080/14427591.2003.9686519

Fogelberg, D., \& Frauworth, S. (2010). A complexity science approach to occupation: Moving beyond the individual. Journal of Occupational Science, 17, 131-139. doi:10.1080/14427591.2010.9686687

Frank, G., \& Muriithi, B. (2015). Theorizing social transformation in occupational science: the American civil rights movement and South African struggle against apartheid as 'occupational reconstructions'. South African Journal of Occupational Therapy, 45, 11-19. doi: 10.17159/2310-3833/2015/v45no1a3

Fransen, H., Pollard, N., Kantartzis, S., \& Viana-Moldes, I. (2015). Participatory citizenship: A critical perspective on client-centred practice. Scandinavian Journal of Occupational Therapy, 22, 260-266. doi: 10.3109/11038128.2015.1020338

Gadamer, H.-G. (2004). Truth and method (J. Weinsherimer \& D. G. Marshall, Trans. 2nd revised ed.). London: Continuum International Publishing Group.

Getz, D. (2007). Event studies: theory, research and policy for planned events. Burlington, MA: Butterworth-Heinemann. 
Hammell, K. W. (2014). Belonging, occupation, and human well-being: An exploration. Canadian Journal of Occupational Therapy, 81, 39-50. doi: $10.1177 / 0008417413520489$

Iwama, M. (2006). The Kawa model. Culturally relevant occupational therapy. Edinburgh: Churchill Livingston Elsevier.

Kantartzis S. (2013). Conceptualising occupation: An ethnographic study of daily life in a Greek town. Leeds: Leeds Metropolitan University.

Kantartzis, S. \& Molineux, M. (2011). The influence of Western society's construction of a healthy daily life on the conceptualisation of occupation. Journal of Occupational Science. 18 (1), pp.62-80. doi.org/10.1080/14427591.2011.566917

Kronenberg, F., Pollard, N., \& Ramugundo, E. (2011). Introduction: Courage to dance politics. In F. Kronenberg, N. Pollard \& D. Sakellariou (Eds.), Occupational Therapy without Borders (pp. 3-16). Edinburgh: Churchill Livingstone Elsevier.

Lauckner, H., Kruper, T. \& Paterson, M. (2011). Conceptualizing community development. Occupational therapy practice at the intersection of health services and community. Canadian Journal of Occupational Therapy, 78, 260-268. doi: $10.2182 /$ cjot.2011.78.4.8

Lawlor, M., \& Mattingly, C. (2001). Beyond the unobtrusive observer: Reflections on researcher-informant relationships in urban ethnography. The American Journal of Occupational Therapy, 55, 147-154. doi:10.5014/ajot.55.2.147

Leclair, L. (2010). Re-examining concepts of occupation and occupation-based models: Occupational therapy and community development. The Canadian Journal of Occupational Therapy, 77, 15-21. Doi: 10.2182/cjot.2010.77.1.3 
Serrata Malfitano, A.P., Esquerdo Lopes, R., Magalhaes, L. \& Townsend, E. (2014). Social occupational therapy: Conversations about a Brazilian experience. Canadian Journal of Occupational Therapy, 81, 298-307. doi: 10.1177/0008417414536712

Motimele, M. R., \& Ramugondo, E. (2014). Violence and healing: Exploring the power of collective occupations. International Journal of Criminology and Sociology, 3, 388401. doi: 10.6000/1929-4409.2014.03.33

O'Reilly, K. (2012). Ethnographic methods (2nd ed.). Abingdon, Oxon: Routledge.

Oldenburg, R. (1997). The great good place (2nd ed.). Cambridge, MA.: Da Capo Press.

Peralta-Catipon, T. (2012). Collective occupations among Filipina migrant workers: Bridging disrupted identities. Occupational Therapy Journal of Research, 32, 14-21. doi:10.3928/15394492-20110805-01

Pickens, N. D., \& Pzur-Barenkow, K. (2009). Co-occupation: Extending the dialogue. Journal of Occupational Science, 16, 151-156. doi:10.1080/14427591.2009.9686656

Pierce, D. (2009). Co-occupation: The challenges of defining concepts original to occupational science. Journal of Occupational Science, 16, 203-207. doi: $10.1080 / 14427591.2009 .9686663$

Pinfold, V. (2000). 'Building up safe havens. . .all around the world': users' experiences of living in the community with mental health problems. Health Place, 6, 201-212. doi:10.1016/S1353-8292(00)00023-X

Ramugondo, E., \& Kronenberg, F. (2015). Explaining collective occupations from a human relations perspective: Bridging the individual-collective dichotomy. Journal of Occupational Science, 22, 3-16. doi: 10.1080/14427591.2013.781920 
Ricoeur, P. (1984). Time and narrative. Volume 1 (K. McLaughlin \& D. Pellauer, Trans.). Chicago: University of Chicago.

Ricoeur, P. (1991). From text to action (J. Blarney \& K. Thompson, Trans.). London: Continuum.

Seamon, D. (2013). Lived bodies, place, and phenomenology: implications for human rights and environmental justice. Journal of Human Rights and the Environment. 4, 143166. doi:10.4337/jhre.2013.02.02

Townsend, E., Cockburn, L. Letts, L., Thibeault, R. \& Trentham, B. (2013). Enabling social change. In E. Townsend \& H. Polatajko (Eds), Enabling Occupation II: Advancing an Occupational Therapy Vision for Health, Well-Being, and Justice through Occupation ( $2^{\text {nd }}$ ed., pp. 153-172). Ottawa, Ontario: CAOT Publications ACE.

Von Scheve, C., \& Ismer, S. (2013). Towards a theory of collective emotion. Emotion Review, 5, 406-413. doi: 10.1177/1754073913484170

Zango Martin, I., Flores Martos, J., Moruno Millares, P., \& Björklund, A. (2015). Occupational therapy culture seen through the multifocal lens of fieldwork in diverse rural areas. Scandinavian Journal of Occupational Therapy, 22, 82-94. doi: $10.3109 / 11038128.2014 .965197$ 